This is not a book for any postgraduate who is still working for any higher examination. It contains statements which will surely cause his downfall, and much that will confuse him. It is not even intended that undergraduates should see it at all. The professional prostatectomist, however, is certain to enjoy either his violent opposition to, or alternately, his complete agreement with a surgeon who is much, and equally, respected by both sides, and who has put into this book a lot more wisdom than the present criticisms may suggest.

W.W.W-D.

\section{DISEASES OF THE EAR, NOSE AND THROAT}

By J. Douglas Mclaggan, C.V.O., M.A., M.B., Ch.B., F.R.C.S., and Josephine Collier, M.A., B.M., Ch.B., F.R.C.S. 2nd Edition. Pp. vi +438 , with 194 illustrations. London: H. K. Lewis \& Co. 1952. 37s. 6d.

The authors of this admirable book are certainly to be congratulated on their concise, clear and up-to-date production. The aims set out in the Preface, viz. to serve as a handbook for practitioners, resident house officers and undergraduates, are completely fulfilled, and advances since publication of the first edition in 1937 have been skilfully incorporated.

Well-balanced views are given on topics on which.controversial papers are still pouring forth, such as the use of antibiotics in infections of the ear, nose and throat, sinusitis in children, fenestration for otosclerosis and the danger of tonsillectomy during epidemics of poliomyelitis. The authors do not hesitate to express their opinions dogmatically, e.g. ' the practice of enucleating tonsils to relieve quinsy is dangerous and unsurgical,' and enthusiastic paediatricians might note that 'indiscriminate myringotomy to a tympanic membrane showing slight infection is to be deplored. Opening the mastoid antrum as a method of treatment of gastro-enteritis without obvious signs of middle ear or mastoid disease is unjustifiable.'

Each section of the book commences with a concise account of the surgical anatomy of the region under consideration and continues with methods of examination, diseases and treatment, with a limited description of those operations which students commonly see in their undergraduate days and about which they could be expected to have some understanding at the beginning of an ear, nose and throat appointment.

There is an excellent chapter on allergic diseases of the nose, in which the importance of endocrine and psychogenic factors is emphasized. The indications for removal of tonsils and adenoids receive careful consideration, and no better via media could be enunciated than the statement that "clear views on the value and limitations of the operation are important to ensure that it does not degenerate into a popular remedy for all ailments. Abuse of the operation discredits a valuable form of treatment.'
The illustrations and X-ray photographs are of uniformly high standard, and the book is in every way worthy of the high reputations of its distinguished writers.

\section{A.C.M.}

\section{GYNAECOLOGY}

By Prof. N. Louros (Athens University). Pp. 407. Athens: Greek Publishing Association. 1952. Approximately $£ 7$ is. od.

The book constitutes a supplement to the author's textbook ' Obstetrics,' published in 1948. Its purpose is to provide for the student, the post-graduate student and the general practitioner the necessary background in gynaecology.

The author has attempted to make this book allinclusive, and in this major undertaking he has succeeded. The book is written in the popular Greek language (unusual for a scientific book). It expresses clearly the author's thoughts on his subject and reflects many years of teaching.

The book has 395 text pages of large size. It is well printed. and illustrated with 403 photographs. As a textbook it is divided into three sections.

Section $I$ includes the chapters of embryology, anatomy and physiology of the female body as far as it concerns its reproductive organs and urogenital system. An account is given of the normal female constitutional types.

In the following chapter (normal female development) the author stresses the role of the 'biocatalytics' (hormones, vitamins, enzymes, etc.) in the development of the female body and the normal changes encountered in the uterine mucosa during the different periods of life and menstrual cycle. A brief description of the gynaecological diagnostic procedure and the hygienic measures for a woman is added to this chapter.

Section 2 starts with the reproductive system biocatalytic disturbances and subsequent constitutional and genital disturbances, their aetiology, diagnosis and treatment.

A detailed chapter follows concerning common gynaecological diseases of the female reproductive and urogenital organs, well illustrated with coloured photographs. The last chapter in this section deals with the problem of castration and the prevention of pregnancy. Both sections are comprehensive, clear and include what a general practitioner and/or a student has to know.

Section 3 is devoted to gynaecology and its relevant surgery (techniques, indications, complications and post-operative care).

There is no doubt that this book will be welcomed by students, general practitioners and specialists. I am sure it will also be of great interest to the man of letters who prefers the modern popular Greek scientific language and will thus popularize unknown knowledge!

$$
\text { S. Bissylas, M.D. }
$$

